\title{
A Nod to disease vectors: mitigation of pathogen sensing by arthropod saliva
}

\author{
Olivia S. Sakhon ${ }^{1+}$, Maiara S. Severo ${ }^{2}$, Michail Kotsyfakis ${ }^{3}$ and Joao H. F. Pedra ${ }^{1}$ \\ ' Department of Microbiology and Immunology, University of Maryland School of Medicine, Baltimore, MD, USA \\ ${ }^{2}$ Department of Entomology, Institute for Integrative Genome Biology, Center for Disease Vector Research, University of California, Riverside, CA, USA \\ ${ }^{3}$ Institute of Parasitology, Biology Centre, Academy of Sciences of the Czech Republic, Ceske Budejovice, Czech Republic
}

\section{Edited by:}

Sukanya Narasimhan, Yale University

School of Medicine, USA

\section{Reviewed by:}

Jason A. Carlyon, Virginia

Commonwealth University School of Medicine, USA

Bindu Sukumaran, Duke-NUS

Graduate Medical School, Singapore

*Correspondence:

Joao H. F. Pedra, Department of

Microbiology and Immunology,

University of Maryland School of

Medicine, 685 West Baltimore Street

HSFI-380, Baltimore, MD 21201, USA

e-mail: jpedra@som.umaryland.edu

${ }^{\dagger}$ Present address:

Olivia S. Sakhon, Division of

Biomedical Sciences, B0600

Statistics Building, University of

California at Riverside, 900 university

Avenue, Riverside, CA 92521, USA
Arthropod saliva possesses anti-hemostatic, anesthetic, and anti-inflammatory properties that facilitate feeding and, inadvertently, dissemination of pathogens. Vector-borne diseases caused by these pathogens affect millions of people each year. Many studies address the impact of arthropod salivary proteins on various immunological components. However, whether and how arthropod saliva counters Nod-like (NLR) sensing remains elusive. NLRs are innate immune pattern recognition molecules involved in detecting microbial molecules and danger signals. Nod1/2 signaling results in activation of the nuclear factor-кB and the mitogen-activated protein kinase pathways. Caspase-1 NLRs regulate the inflammasome a protein scaffold that governs the maturation of interleukin (IL)-1 $\beta$ and IL-18. Recently, several vector-borne pathogens have been shown to induce NLR activation in immune cells. Here, we provide a brief overview of NLR signaling and discuss clinically relevant vector-borne pathogens recognized by NLR pathways. We also elaborate on possible antiinflammatory effects of arthropod saliva on NLR signaling and microbial pathogenesis for the purpose of exchanging research perspectives.

\footnotetext{
Keywords: Nod-like receptors, inflammasome, vector-borne pathogens, vector-borne diseases, arthropod saliva, salivary proteins
}

\section{INTRODUCTION}

Vector-borne diseases impact individuals worldwide and, with their frequencies increasing, they are becoming a crucial public health problem in need of attention (McGraw and O'Neill, 2013). With more than 200 million affected individuals, malaria is spreading rampant in tropical and subtropical regions and dengue fever is following close behind (Table 1). The spread of these illnesses, as well as other vector-borne diseases, has been attributed to rapid globalization, anthropomorphic and environmental changes, and the lack of effective vaccines (Kovats etal., 2001). These maladies have been combated by preventive care and therapeutics (Mejia et al., 2006; Fontaine et al., 2011). In order to develop novel treatments, scientists are continuously attempting to elucidate the mechanism of microbial transmission and aspects of the immune system that are involved in pathogen recognition (Titus and Ribeiro, 1990). Considering the variability between pathogens being transmitted from an arthropod vector to the mammalian host, one can imagine why the development of a vaccine has been an arduous task. However, vaccine development has taken a new route towards a common factor that all disease-transmitting vectors share: saliva. To promote feeding, hematophagous arthropods rely on salivary proteins to not only impart anti-hemostatic capabilities but also anti-inflammatory activities (Ribeiro and Francischetti, 2003; Chmelar et al., 2012).

The relationship between arthropod saliva and components of the vertebrate immune system, such as Toll-like receptors
(TLRs), has been studied. However, one crucial element of innate immunity that still remains vague, with regards to vectorborne diseases, is Nod-like receptors (NLRs). NLRs are an evolutionarily conserved mechanism for pathogen recognition found in both plants and mammals (Nürnberger et al., 2004). Since their discovery, numerous groups have identified the role of NLRs in the recognition of self-derived danger associated molecular patterns (DAMPs), such as ATP, and pathogen associated molecular patterns (PAMPs), such as those from fungi, bacteria, and viruses (Strowig et al., 2012). However, the association between NLRs and vector-borne pathogens still remains unclear. Only recently have researchers drawn attention to the detection of these pathogens by NLRs; even more ambiguous is the connection between salivary proteins and NLRs.

Here, we will address what occurs once a crucial barrier, the skin, is breached by an arthropod vector. We will discuss the subsequent recognition of key vector-borne pathogens by NLRs, and potential mechanisms by which salivary proteins may modulate this interaction. Though not all-encompassing, our focus is on acknowledging major examples by which saliva can modify immunity during infection. For a more comprehensive discussion about proteinaceous and non-proteinaceous salivary molecules, and their function during arthropod feeding, the reader is referred to accompanying reviews in this thematic research topic. 


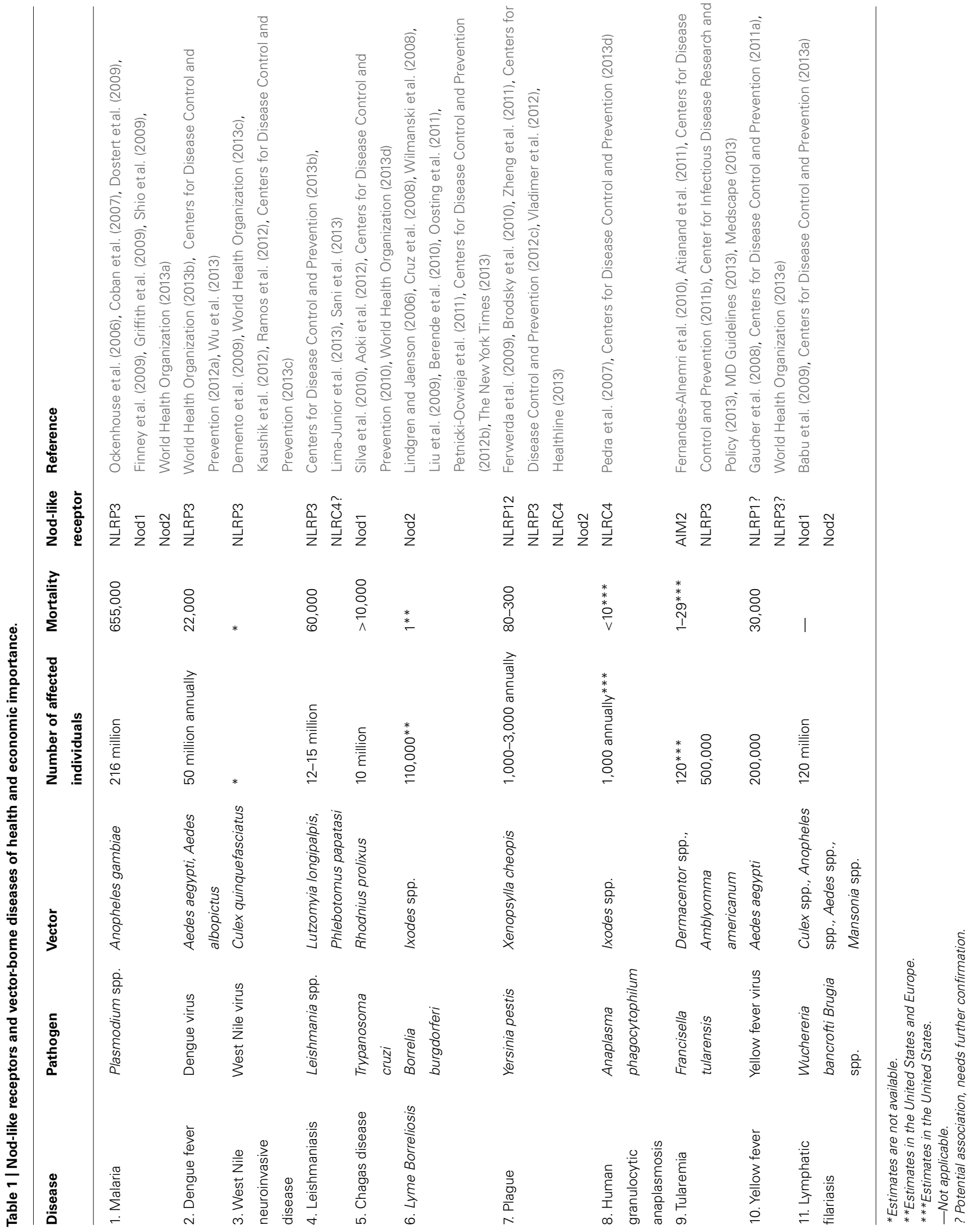




\section{ARTHROPOD SALIVA AND SALIVARY PROTEINS}

Hematophagous arthropods have developed ways to promote the extraction of blood from their hosts while evading detection. The penetration of an arthropod mouthpart into the mammalian host promotes the release of saliva and allows for the acquisition of a blood meal. Though some components of saliva are ubiquitous to all arthropods, specific molecules for different vectors have also been reported (Mans and Francischetti, 2011). For over a hundred years, researchers have identified and dissected the components of saliva and found it to contain anti-hemostatic and anti-inflammatory properties (Sabbatani, 1899). In order to maintain a fluid supply of blood, salivary proteins act as vasodilators, inhibitors of platelet activity, and anti-coagulants (Champagne, 2005). To avoid recognition by the host, saliva not only modulates the inflammatory response, but it can also inhibit immune signaling (Chmelar et al., 2012). Arthropod saliva is composed of a plethora of salivary proteins that possess unique immunomodulatory functions (Table 2). Effects of tick saliva can been seen in a range of immune cell types, such as macrophages, neutrophils, T cells, B cells, and others (Gillespie et al., 2000; Titus et al., 2006; Chen etal., 2012). Salivary proteins with immunomodulatory properties from a myriad of arthropods, include but are not limited to: Rhodnius prolixus, Rhipicephalus appendiculatus, Lutzomyia longipalpis, Aedes aegypti, and Anopheles gambiae have been described. These proteins do not simply target one immune constituent but rather they span the gamut of cellular and molecular immunity.

An example of an immunomodulatory molecule in saliva is evasin. This protein manipulates immune signaling by binding key chemokines, thus, inhibiting the production of cytokines (Frauenschuh et al., 2007; Déruaz et al., 2008). The tick proteins ISL929, ISL1373, sialostatin L, IRS-2, Ir-LBP, and TSLP1 all target neutrophils, usually the first immune cell to respond to a pathogen (Kotsyfakis et al., 2006, 2007; Beaufays et al., 2008; Guo et al., 2009; Sá-Nunes et al., 2009; Chmelar et al., 2011; Schuijt et al., 2011). Antigen presenting cells are the focus of the following salivary molecules: japanin, sialostatin L, PGE 2 , IRIS, Salp15, Ado, and maxadilan (Gillespie et al., 2000; Anguita et al., 2002; Leboulle et al., 2002; Garg etal., 2006; Kotsyfakis et al., 2006, 2007; Hovius et al., 2008; Schuijt et al., 2008; Prevot et al., 2009; Sá-Nunes et al., 2007, 2009; Berende et al., 2010; Fontaine et al., 2011; Oliveira etal., 2011; Preston etal., 2013; Ullmann et al., 2013). Histamine release factor (HRF) and histamine binding proteins (HBP) both act on granule releasing cells (Paesen et al., 1999; Sangamnatdej et al., 2002; Mulenga et al., 2003; Andersen et al., 2005; Dai et al., 2010), while sialostatin L affects cytokine secretion by mast cells (Horka et al., 2012). The complement cascade is a crucial factor involved in directing inflammatory responses through the formation of complexes on the pathogen surface, opsonization, and membrane-attack complex (MAC). ISAC, Salp20, IRAC I/II, TSLP1, and Salp15 can all inhibit the complement system (Valenzuela et al., 2000; Anguita et al., 2002; Garg et al., 2006; Tyson et al., 2007; Schroeder et al., 2007; Schuijt et al., 2008; Hovius et al., 2008; Berende et al., 2010). Salivary constituents not only aim for the innate immune system, but they also act on the adaptive immunity. Salivary components may act on T cells, B cells, or antibodies, as is the case with IL-2 binding protein, IsSMase, IRIS, BIP, Salp15,
IgG-BP, and maxadilan (Wang and Nuttall, 1995, 1999; Wang et al., 1998; Gillespie et al., 2001; Hannier et al., 2004; Alarcon-Chaidez et al., 2009; Prevot et al., 2009; Fontaine et al., 2011).

Although some of these proteins have overlapping cellular targets, their activity at the molecular level demonstrate some variability. For instance, ISAC, Salp20, IRAC I/II, TSLP1, and Salp15 inhibit complement through different mechanisms. ISAC, Salp20, and IRACI/II dissociate the crucial complement convertase molecule C3 (Paesen et al., 1999; Lögdberg and Wester, 2000; Valenzuela et al., 2000; Anguita et al., 2002; Leboulle et al., 2002; Sangamnatdej et al., 2002; Andersen et al., 2005; Garg et al., 2006; Daix et al., 2007; Schroeder et al., 2007; Tyson et al., 2007, 2008; Déruaz etal., 2008; Schuijt et al., 2011). However, TSLP1 and Salp15 target the complement pathway by inhibiting mannosebinding lectin and MAC, respectively (Schuijt et al., 2008). Even within the same organism, salivary proteins can influence $\mathrm{T}$ cells in different ways. IL-2 binding, does as its name implies, blocks IL-2 while IsSMase affects $\mathrm{T}$ cells by increasing IL-4 (Gillespie et al., 2001; Alarcon-Chaidez et al., 2009). Immune regulation by the saliva of arthropod vectors discussed in this review consists of: (1) impediment of attachment, (2) reduction of oxidants, (3) decrease of pro-inflammatory enzymatic activity, (4) modification of cytokine levels, (5) attenuation of co-receptor binding, and (6) sequestration of pro-inflammatory mediators from binding to their receptors (Table 2 ).

Modulation of host immunity favors arthropod blood-feeding (Fontaine etal., 2011). This occurrence was first observed upon infection with Leishmania parasites (Titus and Ribeiro, 1988). More recently, studies demonstrated that enhancement of pathogen infection by saliva seems universal (Francischetti et al., 2009; Fontaine et al., 2011). Increased infectivity in the presence of arthropod saliva has been shown for pathogens transmitted by sandflies, mosquitoes and ticks (Titus et al., 2006). Specifically, mosquito saliva enhances transmission of malaria parasites (Vaughan et al., 1999), West Nile (Styer et al., 2011), La Crosse (Osorio etal., 1996) and Cache Valley (Edwards etal., 1998) viruses. Similarly, tick saliva counteracts host-derived inflammation (Francischetti et al., 2009; Fontaine et al., 2011) by impairing the function of innate and adaptive immune cells (de Silva et al., 2009), and inhibiting cytokine secretion (Fontaine et al., 2011). Borrelia burgdorferi - the Lyme disease agent - appears shielded by a salivary protein called Salp15 from the tick I. scapularis, and in turn, protected from antibody-mediated killing (Ramamoorthi et al., 2005) and dendritic cell function (Valenzuela et al., 2000; Hovius et al., 2008). However, this effect is not unique to Salp15 because sialostatin L2, another protein, also facilitates pathogen transmission at the skin site (Kotsyfakis et al., 2010). Interestingly, in the Aedes aegypti mosquito model, saliva appears to protect dendritic cells from infection with dengue virus in vitro (Ader et al., 2004).

An intriguing aspect of the pathogen-saliva interaction lies in the response of the skin to infection (Frischknecht, 2007; Krause etal., 2009). During the infectious blood meal, the arthropod mouthpart dilacerates and penetrates the epidermis and reaches the dermis. The skin injury leads to a local inflammatory response involving secretion of chemokines, cytokines, and antimicrobial molecules as well as dermal mast cell degranulation, fluid 


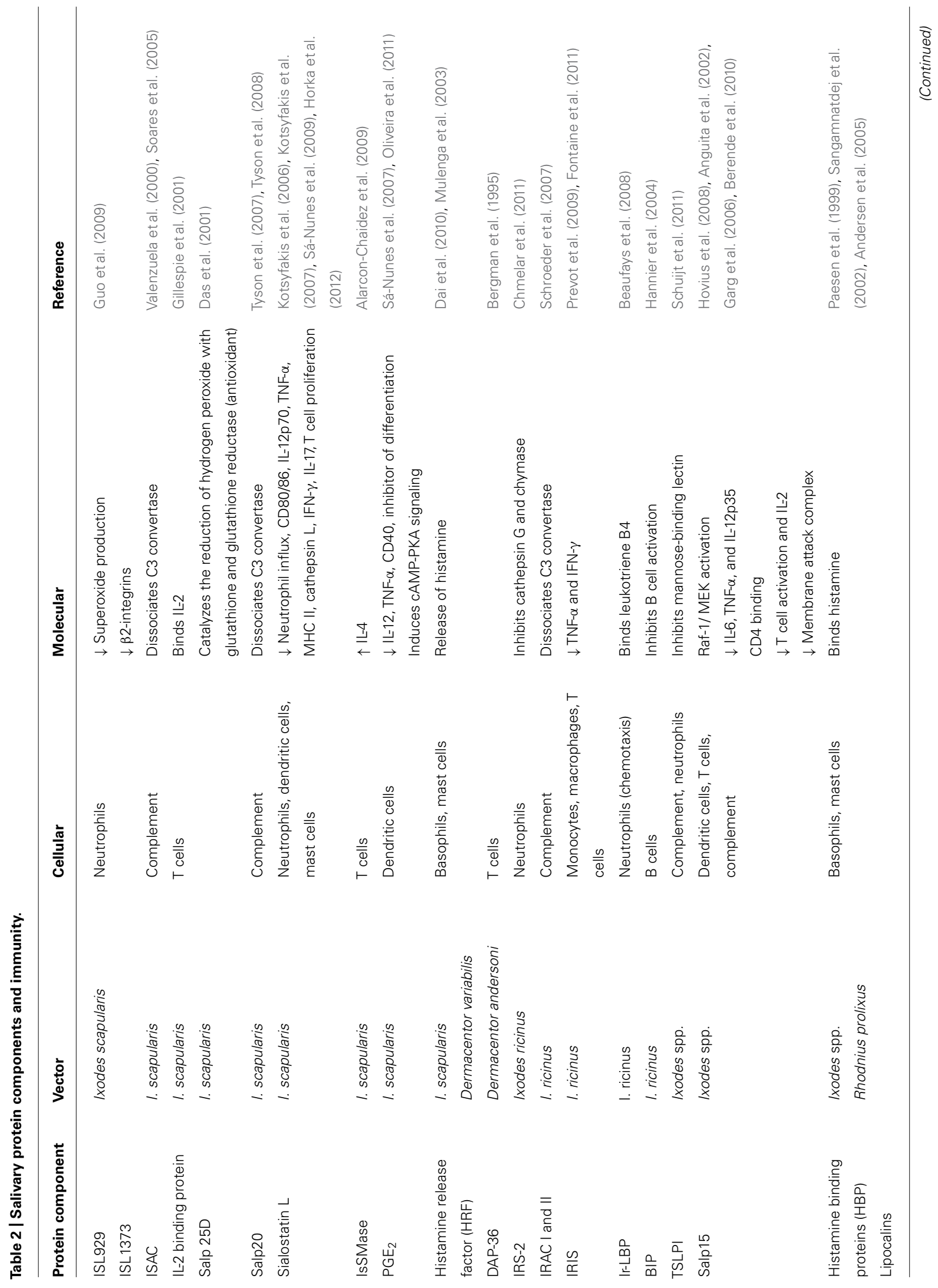




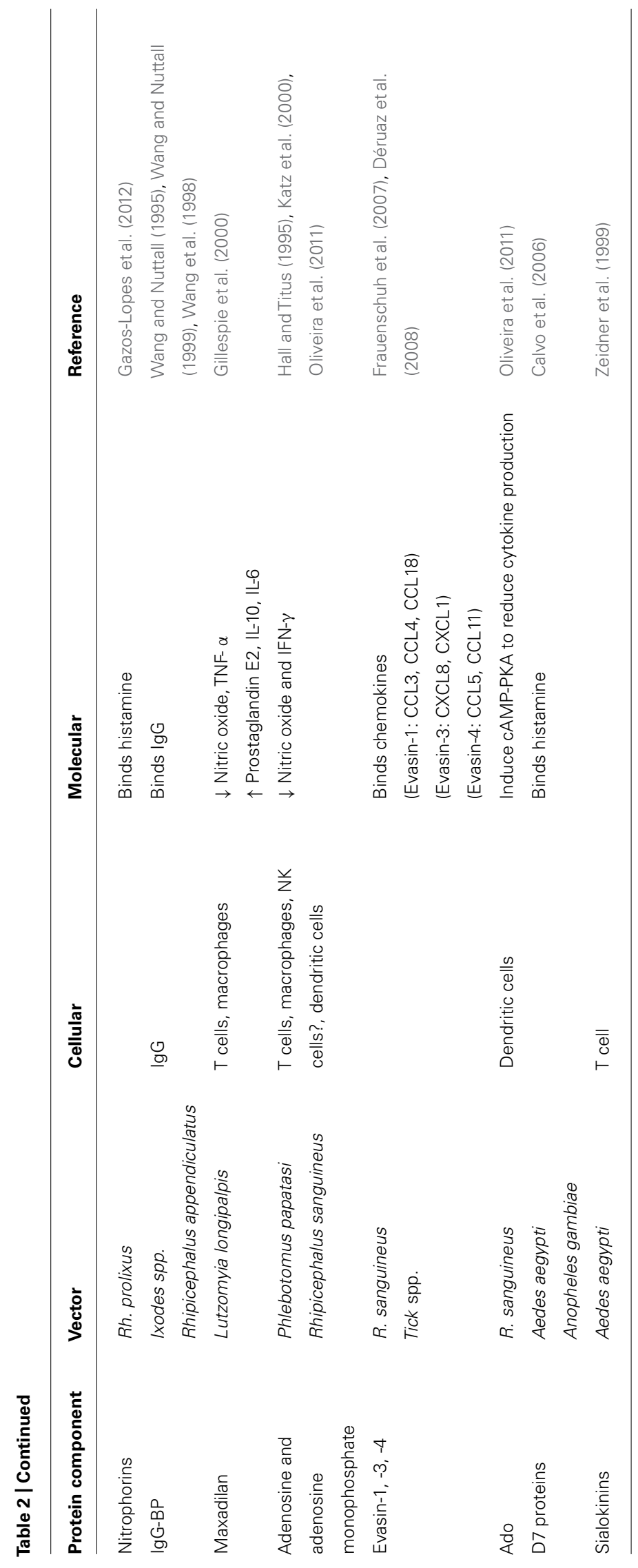


extravasation and neutrophil influx (Boulanger et al., 2006; Rubin and Strayer, 2012). This response has a major impact on furthering the establishment of infection because pathogen inoculation follows an arthropod bite. Cellular responses promoted by mast cells, neutrophils, dendritic cells and infiltrated macrophages aim not only to repair the skin injury, but also remove a microbial threat during vector transmission. This series of steps also reverberates on the later activation of adaptive immunity and recruitment of cell types that may promote pathogen propagation in the host, especially for intracellular microorganisms.

\section{NOD-LIKE RECEPTORS}

Approximately two decades ago, a group of sensors were added to the pattern recognition receptor family, expanding what was known about intracellular recognition of endogenous and exogenous molecules (Inohara et al., 1999). NLRs are appropriately named due to their characteristic nucleotide binding and oligomerization domain (NOD). NLRs may also contain leucinerich repeats (LRR) at their C-terminus and a variable effector domain at their $\mathrm{N}$-terminal end, all of which play a role in pathogen recognition and immunity (Moreira and Zamboni, 2012). Although 22 human and 30 mouse NLRs been discovered, to stay within the scope of our review, we will only address those that have been associated with crucial vector-borne diseases (Table 1; Schroder and Tschopp, 2010; Moreira and Zamboni, 2012).

\section{NOD1 AND NOD2}

Nod1 and Nod2 are crucial for the recognition of peptidoglycan components (Figure 1). Signaling through Nod1 and Nod2 begins with the initiation of Nod1 by D-glutamyl-meso-diaminopimelic acid (DAP) and/or Nod2 by muramyl dipeptide (MDP; Chamaillard et al., 2003; Girardin et al., 2003a). While the NOD portion acts as a receiver in the presence of these pathogenic molecules, the effector CARD domain(s) of Nod1 and Nod2 perpetuate the signal transduction by interacting with receptor-interacting serine/threonine protein kinase-2 (RIP2/RICK; Kobayashi et al., 2002). Classically, RIP2/RICK is polyubiquitinated by TNF receptor-associated factor 6 (TRAF6), this signal is required for the recruitment of the adaptor molecules TAK1-binding protein 2 and 3 (TAB2/3) and activation of TAK1 (Besse et al., 2007). Together this forms the TGF- $\beta$-activated kinase 1 (TAK1) complex that promotes the degradation of the inhibitor of nuclear factor $(\mathrm{NF})-\kappa \mathrm{B}$, thereby allowing the translocation of $\mathrm{NF}-\kappa \mathrm{B}$ into the nucleus. This is only one signaling cascade that is activated by Nod1/2, the mitogen-activated protein kinases (MAPK) pathway is another branch that can be driven by these NLRs (Pauleau and Murray, 2003; Park et al., 2007). Nod1 and Nod2 can activate three key MAPK: extracellular signal-related kinases (ERK), Jun amino-terminal kinases (JNK), and p38. The latter two can also be signaled by Nod2 through the adaptor caspase recruitment domain-containing protein 9 (CARD9; Colonna, 2007). The activation of each pathway results in the expression of proinflammatory mediators, such as cytokines and antimicrobial peptides. Nod 1 and Nod 2 can be regulated by A20-mediated ubiquitin modifications and caspase-12 inhibition of RIPK2-TRAF6 complex formation (Hitotsumatsu et al., 2008; LeBlanc et al., 2008).
Recent developments have identified a new role for Nod 1 and Nod 2 in the recognition of pathogens lacking peptidoglycan. Studies have reported that Nod proteins can respond to protozoan parasites, like Toxoplasma gondii (Shaw et al., 2009). Surprisingly, Nod 2 has been shown to respond to single-stranded RNA (Sabbah et al., 2009). The activation of Nod 2 in this case is dependent upon the mitochondrial antiviral signaling protein MAVS and results in the facilitation of interferon regulatory factor 3 (IRF3) mediated interferon (IFN) gene expression. Another protective measure that Nod 1 and Nod 2 are involved in is the induction of autophagy related 16-Like 1 (ATG16L1)-dependent autophagy in response to bacterial invasion, such is the case with Listeria monocytogenes (Travassos et al., 2010). Nod1 and Nod2 are gradually revealing their complex nature. Most commonly acknowledged as a sensor for peptidoglycan molecules, there is also debate that Nod1 and Nod2 may possess regulatory abilities (Murray, 2005). Studies regarding Nod1 and Nod2 function are continuously being assessed in order to develop a comprehensive understanding of these key proteins.

\section{INFLAMMASOME}

The inflammasome is a potent innate immune structure characterized by its ability to activate pro-caspase- 1 in response to PAMPs or DAMP (Figure 2). The inflammasome scaffold is created by the oligomerization and recruitment of several proteins. One component, the receptor, defines the inflammasome; it can either originate from the NLR family or contain the HIN-200 domain (Lamkanfi and Dixit, 2011). Depending upon the receptor type, the adaptor molecule ASC may or may not be implicated. Since ASC possesses both a pyrin and CARD domain, it facilitates the association between the CARD-containing pro-caspase-1 and a receptor lacking the CARD domain (Schroder and Tschopp, 2010). Classically, inflammasome-mediated cytokine secretion is the product of a two-tiered signaling system (Figure 2; Franchi et al., 2012). The first signal concerns the activation the NF- $\kappa \mathrm{B}$ pathway in order to promote the gene expression of IL-1 $\beta$ and IL-18 and other pro-inflammatory genes, such as Nlrp3. The second signal involves the assembly of the inflammasome, which results in the secretion of the abovementioned cytokines. Common to all canonical inflammasomes is the presence of the enzyme pro-caspase-1. Caspase- 1 is responsible for the maturation of the pro-inflammatory cytokines interleukin (IL)-1 $\beta$ and IL-18 and the inflammation-related cell death process termed pyroptosis (Davis et al., 2011). Other caspases have also been shown to be involved in the inflammasome signaling pathway. Caspase-11 was recently discovered to modulate caspase- 1 in response to certain Gram-negative bacteria, such as Citrobacter rodentium (Kayagaki et al., 2011; Rathinam et al., 2012). Another non-canonical inflammasome involves caspase-8. Caspase- 8 is a negative regulator of pro-inflammatory NLRP3 inflammasome activity (Kang et al., 2013). During macrophage infection with Francisella tularensis subspecies novicida, caspase-8 can form a complex with AIM2 and ASC (Pierini et al., 2012). Caspase- 8 associates with dectin-1 in the presence of fungi and mycobacteria (Gringhuis et al., 2012). Caspase- 5 can also bind with an inflammasome, namely NLRP1 (Martinon et al., 2002). Not only can caspases bind to the inflammasome, they can also be cleaved by the caspase- 1 component of 


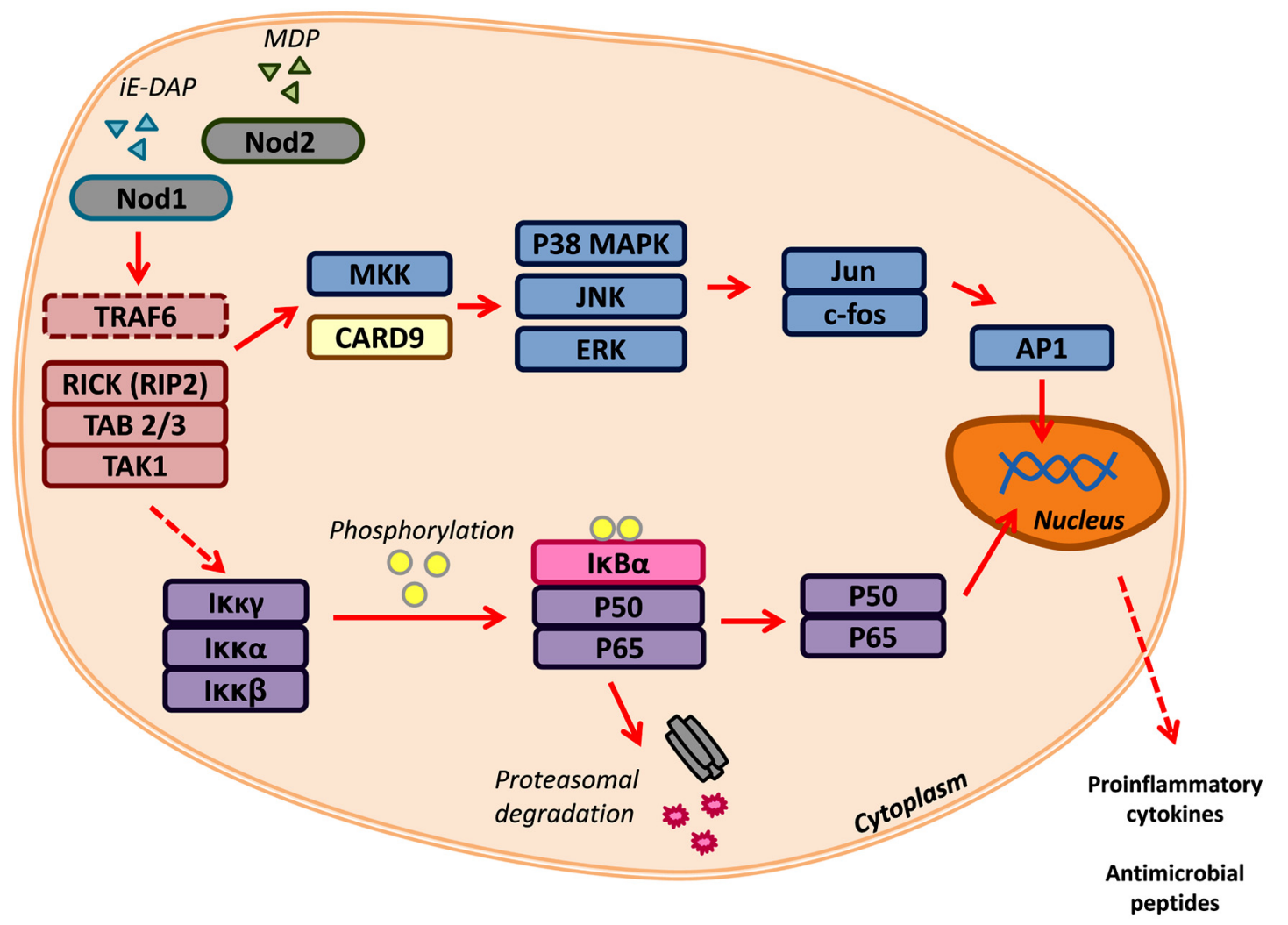

FIGURE 1 | Nod1 and Nod2 signaling. Nod1 and Nod2 are activated by the peptidoglycan components iE-DAP and MDP, respectively. Recognition of PAMPs triggers TRAF6, RICK/RIP2, TAB 2/3, and TAK1.

These can signal downstream to two major signaling networks: (1) MAP kinase and the (2) NF-kB pathways. Transcription factors, such as AP1 and the NF-kB complex (p50/p65), translocate to the nucleus to promote the transcription of pro-inflammatory cytokines and antimicrobial peptides. the protein scaffold, similar to IL-1 $\beta$. This phenomenon is seen in caspase-7 activation by caspase-1 during Legionella pneumophila infection (Akhter etal., 2009). Taken together, multiple checkpoints are crucial for inflammasome regulation due to its strength as a pro-inflammatory initiator.

\section{RECOGNITION OF VECTOR-BORNE PATHOGENS BY NLRS}

Medically relevant vector-borne pathogens have plagued the health of individuals all over the globe (Table 1). Even more concerning is the rate at which these diseases are escalating and claiming the lives of thousands of people (Hotez et al., 2009). The relationship between these daunting pathogens and recognition by NLRs is not fully understood.

\section{NOD1 AND NOD2}

Being one of the first NLRs discovered, many studies have been aimed to the role of Nod1 in the context of bacterial pathogenesis (Chamaillard et al., 2003; Girardin et al., 2003b; Ray et al., 2009). Research involving the sensing of bacteria in the intracellular compartment of a wide range of cell types has dominated the Nod1 field. However, Silva et al. (2010) were able to classify Nod1 as a crucial component for the resistance to the parasite Trypanosoma cruzi. T. cruzi is transmitted by the kissing bug, Rhodnius prolixus, primarily in Latin American countries. It is the causative agent of Chagas disease, which can be characterized by fever, edema, or inflammation in the heart and/or brain (Centers for Disease Control and Prevention, 2010). These authors observed, through the use of Nod1 $1^{-/-}$and Nod2 $2^{-/-}$mice, that IL-12 and TNF- $\alpha$ levels were reduced after infection. Since nitric oxide is a key factor for T. cruzi containment, interferon gamma (IFN- $\gamma$ ) was used to treat Nod1 $1^{-/}$and Nod2 $2^{-/}$bone marrow-derived macrophages. This resulted in a high load of parasites for the Nod $1^{-/}$macrophage, highlighting the specificity of Nod1, not Nod2, for T. cruzi infection.

B. burgdorferi is a spirochete transmitted by Ixodes spp. Infection by $B$. burgdorferi causes Lyme disease, the most common vector-borne disease north of the equator (Parola and Raoult, 2001; Lindgren and Jaenson, 2006; Berende et al., 2010). Lyme disease can manifest into a three stage infection: (1) erythema migrans is characterized by localized infection, (2) early disseminated infection results in inflamed joints and CNS, and (3) persistent infection, which consists of chronic inflammation of joints and the CNS and sensory polyneuropathy (Berende et al., 2010). It has been established that TLR2 plays an important role in the recognition of $B$. burgdorferi. Recent evidence points to Nod2 as an important factor in the sensing of this pathogenic spirochete (Petnicki-Ocwieja et al., 2011). Nod2 is upregulated in mouse microglia and individuals with mutated Nod2 were not 


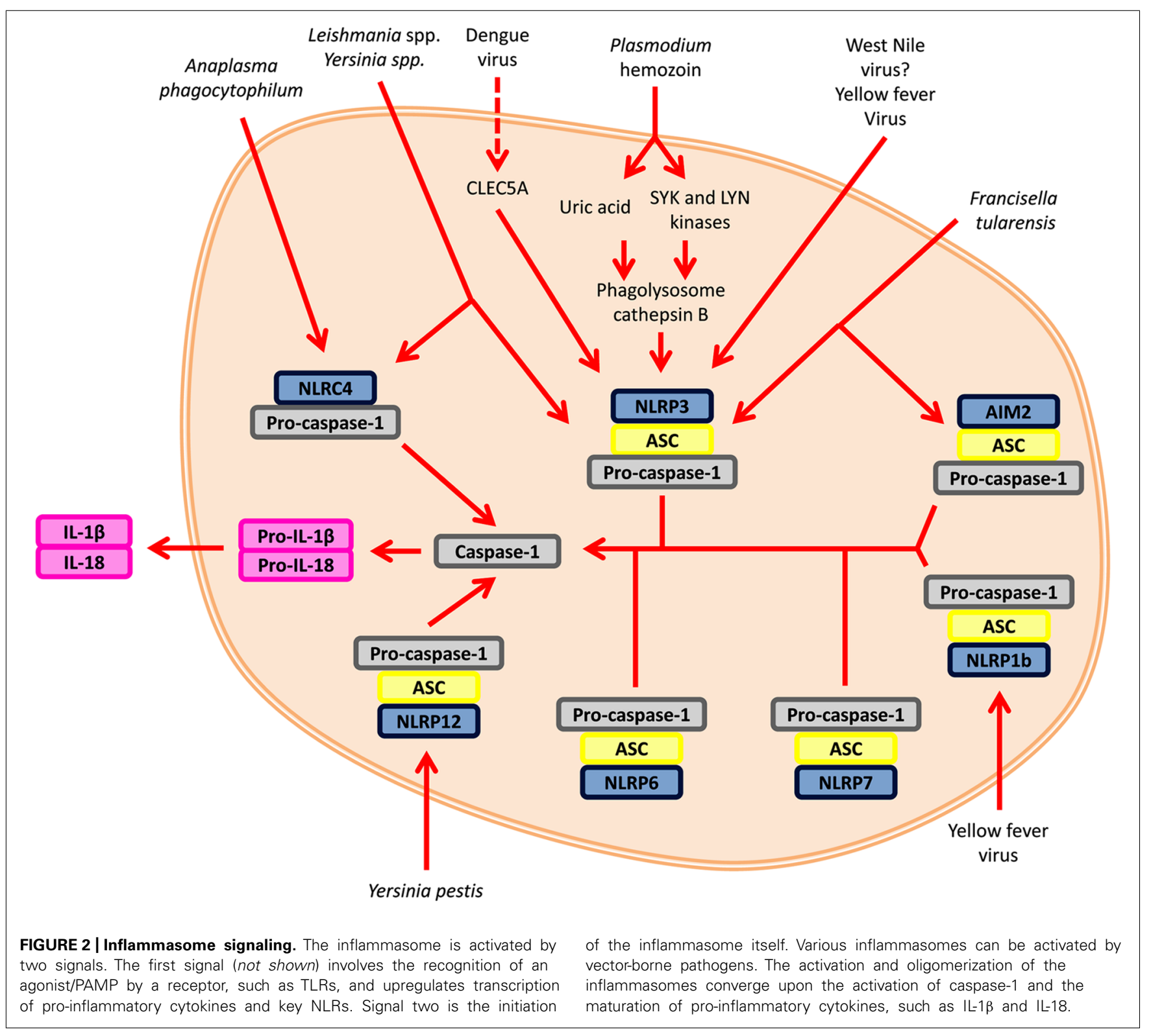

able to mount an efficient cytokine response after infection with B. burgdorferi (Sterka et al., 2006; Oosting et al., 2010). The plague causing vector-borne pathogen Yersinia has also been shown to be recognized by Nod2 (Ferwerda et al., 2009).

Nod1 and Nod2 also appear to possess redundancy because they are able to detect similar arthropod-borne pathogens. Individuals who encountered an antigenic component from the Brugia malayi adult demonstrated an increase in Nod1 and Nod2 expression (Babu et al., 2009). Brugia and Wuchereria bancrofti species can cause lymphatic filariasis which can manifest as elephantiasis, lymphedema, and hydrocele (Centers for Disease Control and Prevention, 2013a). Independently, the obligate intracellular pathogen Anaplasma phagocytophilum, transmitted by Ixodes spp., is involved in the increased expression of Rip2, a critical molecule in Nod1 and Nod2 signaling (Sukumaran et al., 2012). More importantly, the ability for Rip $2^{-/-}$mice to control and clear
A. phagocytophilum was severely hindered. The Plasmodium parasite is also detected by Nod proteins (Coban et al., 2007). Certain instances result in upregulation of Nod2 in the presence of Plasmodium sporozoites, while in other cases Nod1 and Nod2 confer changes in cytokines but do not promote survival after infection (Ockenhouse et al., 2006; Finney et al., 2009).

\section{NLRP1 INFLAMMASOME}

The NLRP1 inflammasome was the first to be characterized (Martinon et al., 2002). NLRP1 has been shown to recognize the Bacillus anthracis lethal toxin and, like Nod2, MDP (Boyden and Dietrich, 2006; Faustin et al., 2007). The activation of pro-caspase- 1 activity elicited by these bacterial components is distinct. Cleavage of the NLRP1 inflammasome by the lethal toxin is required for inflammasome activation, as mutation of NLRP1 demonstrates reduced caspase-1 activation (Levinsohn 
et al., 2012). On the other hand, MDP activation of NLRP1 requires the presence of $\mathrm{MDP}$ and ribonucleoside triphosphates (Faustin et al., 2007). It was observed that a cohort given a yellow fever vaccine showed upregulation of caspase- 1 and caspase- 5 . These two caspases are present in the NLRP1 inflammasome. This indicates that the NLRP1 inflammasome may be activated by the yellow fever virus. This virus is transmitted by the mosquito Aedes aegypti. Inoculation of yellow fever virus by a mosquito can lead to mild reactions, such as fever, ache, and nausea, or more serious ones, such as organ failure (Centers for Disease Control and Prevention, 2011a). More studies need to be done in order to clarify what components trigger a NLRP1 inflammasome response to the yellow fever virus.

\section{NLRP3 INFLAMMASOME}

Of all NLRs, NLRP3, currently, has the most known associations with vector-borne diseases. It is well known that NLRP3 is triggered by three signals: (1) potassium efflux, (2) phagolysosomal disruption, and (3) ROS production (Schroder and Tschopp, 2010). Recently, mitochondrial DNA and calcium levels were suggested to be other activators of the NLRP3 inflammasome (Rossol et al., 2012; Shimada et al., 2012). The malarial parasite has demonstrated the ability to activate the NLRP3 inflammasome through the crystalline particle hemozoin (Dostert et al., 2009; Griffith et al., 2009; Shio et al., 2009). Monosodium urate (uric acid), together with hemozoin, has also been reported to result in pro-inflammatory reactions through the MAPK signaling pathway (Griffith etal., 2009; Shio etal., 2009). Hemozoin is a byproduct of heme detoxification by Plasmodium. The phagocytosis of hemozoin initiates signals through spleen tyrosine kinase (Syk) and v-yes-1 Yamaguchi sarcoma viral related oncogene homolog (Lyn), tyrosine kinases, in order to initiate the NLRP3 inflammasome (Shio et al., 2009). Another mosquito-borne pathogen, the dengue virus is transmitted by $A$. aegypti or A. albopictus. Dengue virus can cause dengue fever or dengue shock syndrome. Wu et al. (2013) elucidated that, in human macrophages, dengue virus can signal through Syk-coupled C-type lectin 5A (CLEC5A) to induce NLRP3-mediated cytokine secretion and pyroptosis. Though not much is known about yellow fever virus and the inflammasome, one study shows that vaccination with a live attenuated yellow fever vaccine is able to increase the expression caspase-1 associated with the NLRP3 inflammasome (Gaucher et al., 2008).

IL-1 $\beta$ is crucial for the protection of the CNS from West Nile neuroinvasive disease (Ramos et al., 2012). Moreover, it was shown that this phenomenon is specific for NLRP3 inflammasome mediated IL-1 $\beta$ secretion. Additionally, IL-1 $\beta$ combined with type I IFN results in the reduction of West Nile virus infection. Non-mosquito-borne pathogens also influence NLRP3 activity. Infection by Leishmania spp., transmitted by the sandfly Lutzomyia longipalpis, can result in skin, organ, and/or mucosal complications (Centers for Disease Control and Prevention, 2013b). In murine macrophages, Sani et al. (2013) found that the expression of Nlrp3 is increased after exposure to Leishmania major. Furthermore, Lima-Junior et al. (2013) confirmed NLRP3 activation after L. amazonensis infection that led to the protective restriction of parasites. Another non-mosquito-borne pathogen is Francisella tularensis, which is commonly transmitted by ticks. Tularemia can cause sores and respiratory complications. Uniquely in human leukemia cell line (THP-1) but not in mouse cells, Francisella is capable of activating the NLRP3 inflammasome (Atianand et al., 2011). Supporting this, the use of NLRP3 inflammasome inhibitors and Nlrp3 siRNA revealed that the IL-1 $\beta$ secretion in response to Francisella was lessened. The type III secretion system (T3SS) from Yersinia pestis is also able to activate the NLRP3 inflammasome in vitro (Brodsky et al., 2010). With the addition of $\mathrm{KCl}$, the NLRP3 inflammasome activity was nullified. However, other inflammasomes are also involved in the detection of Yersinia as well. Although Nod2 has been acknowledged as a protein that recognizes Borrelia, there is controversy on whether inflammasomes are activated in response to this vector-borne pathogen. Though independent of the NLRP3 inflammasome, multiple groups have found that caspase- 1 is activated after exposure to Borrelia while another group was unable to detect caspase-1 dependence (Cruz et al., 2008; Liu et al., 2009; Oosting et al., 2011).

\section{NLRC4 INFLAMMASOME}

The CARD-containing NLRC4 inflammasome mediates proinflammatory responses to the recognition of flagellin and type III/IV secretion systems from gram-negative bacteria (Schroder and Tschopp, 2010). NLRC4, also called IPAF, inflammasome confer protection against bacteria, such as Salmonella typhimurium and Pseudomonas aeruginosa (Miao et al., 2008). It is also able to directly and indirectly associate with pro-caspase-1, via its CARD domain or the adaptor molecule ASC, respectively. Additionally, another level of specificity is added by the NLRC4 interaction with NAIP5 or NAIP2, which modifies NLRC4 activation in response to flagellin and the type III secretion system (T3SS), respectively (Zhao etal., 2011). As of yet, NLRC4 has been implicated in two vector-borne illnesses, Human granulocytic anaplasmosis and Leishmaniasis. Nlrc $4^{-/-}$mice showed heightened susceptibility to Anaplasma phagocytophilum and decreased levels of IL-18 relative to the wild-type. However, the effect of NLRC4 was partial; thereby, suggesting additional mechanisms of inflammasome activation (Pedra etal., 2007). Sani etal. (2013) found that Nlrc4 expression increased after exposing macrophages to L. major. As was previously mentioned, $Y$. pestis is able to activate several inflammasomes, and it is also able to combat this recognition with effector proteins (Brodsky et al., 2010). The NLRC4 inflammasome is another protein complex involved in the recognition of $Y$. pestis T3SS (Brodsky et al., 2010).

\section{NLRP12 INFLAMMASOME}

The NLRP12 inflammasome is a member of the NLR family that has been suggested to reduce and potentiate inflammatory cytokine secretion (Wang et al., 2002; Lich et al., 2008; Arthur et al., 2010; Zaki et al., 2011; Allen et al., 2012). Currently, NLRP12 has been shown to play a role in hereditary period fever syndromes, but very little is known with respect to vector-borne diseases. Vladimer et al. (2012) discovered that NLRP12 regulates IL-18 secretion in response to $Y$. pestis. More specifically, after infection of Nlrp $12^{-/-}$mice with $Y$. pestis, they observed an increase in bacterial load and death which was associated with decreased levels of IL-18 and IL-1 $\beta$. 


\section{NON-NLR INFLAMMASOME}

The AIM2 (absent in melanoma 2) inflammasome does not contain the typical NLR domain as do other inflammasomes. Rather, it carries the HIN-200 domain (Case, 2011). In particular, AIM2 is known for sensing double stranded DNA in the cytosol (Bauernfeind etal., 2011). The formation of the AIM2 inflammasome consists of the AIM2 receptor, ASC, and pro-caspase-1. Upon recognition of cytoplasmic DNA, AIM2 is able to coordinate pyroptosis and the release of IL-1 $\beta$ and IL-18 via pro-caspase-1 maturation (Davis et al., 2011). Of the vector-borne pathogens discussed in this review, AIM2 is able to recognize F. tularensis in mouse macrophages (Fernandes-Alnemri et al., 2010). Moreover, IRF3 is needed for a type 1 IFN response to help mount an effective AIM2-dependent activation after F. tularensis infection (Fernandes-Alnemri et al., 2010).

\section{CONCLUDING REMARKS}

The importance of NLRs and vector saliva has been demonstrated through numerous elaborate studies. Further research in this area has the potential to reveal more intricate relationships, as well as the salivary effectors that can modulate these interactions. This review has highlighted the role of NLRs and salivary components in vector-borne diseases. Due to the vast amount of literature available in the field of arthropod saliva and the diverse mechanisms of vertebrate-host immunomodulation, we elected to focus only on those pertinent to the vectors discussed here. Elucidating the mechanisms behind NLR recognition and salivary modulation of pathogenic agents will shed light on the fundamental basis of pathogen-vectorhost interactions. Additionally, it should provide novel targets

\section{REFERENCES}

Ader, D. B., Celluzzi, C., Bisbing, J., Gilmore, L., Gunther, V., Peachman, K. K., et al. (2004). Modulation of dengue virus infection of dendritic cells by Aedes aegypti saliva. Viral Immunol. 17, 252-265. doi: 10.1089/0882824041310496

Akhter, A., Gavrilin, M. A., Frantz, L., Washington, S., Ditty, C., Limoli, D., et al. (2009). Caspase-7 activation by the Nlrc4/Ipaf inflammasome restricts Legionella pneumophila infection. PLoS Pathog. 5:e1000361. doi: 10.1371/journal.ppat.1000361

Alarcon-Chaidez, F. J., Boppana, V. D., Hagymasi, A. T., Adler, A. J., and Wikel, S. K. (2009). A novel sphingomyelinase-like enzyme in Ixodes scapularis tick saliva drives host CD4 $\mathrm{T}$ cells to express IL4. Parasite Immunol. 31, 210219. doi: 10.1111/j.1365-3024.2009. 01095.x

Allen, I. C., Wilson, J. E., Schneider, M., Lich, J. D., Roberts, R. A, Arthur, J. C., et al. (2012). NLRP12 suppresses colon inflammation and tumorigenesis through the negative regulation of noncanonical NF- $\mathrm{BB}$ signaling. Immunity 36, 742-754. doi: 10.1016/j.immuni.2012.03.012

Andersen, J. F., Gudderra, N. P., Francischetti, I. M. B., and Ribeiro, J. M. C. (2005). The role of salivary lipocalins in blood feeding by Rhodnius prolixus. Arch. Insect Biochem. Physiol. 58, 97-105. doi: 10.1002/arch.20032

Anguita, J., Ramamoorthi, N., Hovius, J. W. R., Das, S., Thomas, V., Persinski, R., et al. (2002). Salp15, an Ixodes scapularis salivary protein, inhibits CD4(+) T cell activation. Immunity 16, 849-859. doi: 10.1016/S1074-

Aoki, M. P., Carrera-Silva, E. A., Cuervo, H., Fresno, M., Gironès, N., and Gea, S. (2012). Nonimmune cells contribute to crosstalk between immune cells and inflammatory mediators in the innate response to Trypanosoma cruzi infection. J. Parasitol. Res. 2012, 737324. doi: 10.1155/2012/737324

Arthur, J. C., Lich, J. D., Ye, Z., Allen, I. C., Gris, D., Wilson, J. E., et al. (2010). NLRP12 controls dendritic and myeloid cell migration to affect contact hypersensitivity. J. Immunol. 185, 4515-4519. doi: 10.4049/jimmunol.1002227 7613(02)00325-4

for therapeutic intervention of devastating vector-borne diseases.

Based on our current knowledge, we suggest that arthropod saliva could regulate NLR inflammasome activity during pathogen transmission or after infection. Vector saliva has been shown to minimize reactive oxygen species (ROS; Guo et al., 2009). ROS has been identified as an agonist for inflammasome activation; therefore salivary proteins can potentially reduce ROS to decrease inflammasome activity. Another mechanism by which arthropod saliva can hinder the inflammasome is by acting on caspase- 1 . Caspase-1, the key enzymatic component of the inflammasome, is a member of the cysteine protease family. Salivary proteins have demonstrated the ability to target cysteine proteases, such as sialostatin L inhibition of cathepsin L (Kotsyfakis et al., 2006). Of interest, the same protein exhibits anti-inflammatory effects. Thus, it is plausible that sialostatins block caspase- 1 activation and subsequent IL-1 $\beta$ and IL-18 secretion. A better understanding of salivary components regulating vector-borne pathogens and NLR interaction could allow us to gain a foothold on controlling these infectious diseases.

\section{AUTHOR CONTRIBUTIONS}

Olivia S. Sakhon, Maiara S. Severo, Michail Kotsyfakis, and Joao H. F. Pedra wrote the manuscript. Olivia S. Sakhon created the tables and figures.

\section{ACKNOWLEDGMENTS}

This work was supported by a public health service grant R01 AI093653 to Joao H. F. Pedra; and by an International Fellowship from the American Association of University Women to Maiara S. Severo.

Atianand, M. K., Duffy, E. B., Shah, A., Kar, S., Malik, M., and Harton, J. (2011). Francisella tularensis reveals a disparity between human and mouse NLRP3 inflammasome activation. J. Biol. Chem. 286, 39033-39042. doi: 10.1074/jbc.M111.244079

Babu, S., Bhat, S. Q., Pavan Kumar, N., Lipira, A. B., Kumar, S. Karthik, C., et al. (2009). Filarial lymphedema is characterized by antigen-specific Th1 and Th17 proinflammatory responses and a lack of regulatory $\mathrm{T}$ cells. PLoS Negl. Trop. Dis. 3:e420. doi: 10.1371/journal.pntd.0000420

Bauernfeind, F., Ablasser, A., Bartok, E., Kim, S., Schmid-Burgk, J., Cavlar, T., et al. (2011). Inflammasomes: current understanding and open questions. Cell. Mol. Life. Sci. 68, 765-783. doi: 10.1007/s00018-010-0567-4

Beaufays, J., Adam, B., MentenDedoyart, C., Fievez, L., Grosjean, A., Decrem, Y., et al. (2008). IrLBP, an Ixodes ricinus tick salivary LTB4-binding lipocalin, interferes with host neutrophil function. PLoS ONE 3:e3987. doi: 10.1371/journal.pone.0003987
Berende, A., Oosting, M., Kullberg, B.J., Netea, M. G., and Joosten, L. A B. (2010). Activation of innate host defense mechanisms by Borrelia. Eur. Cytokine Netw. 21, 7-18. doi: 10.1684/ecn.2009.0179

Bergman, D. K., Ramachandra, R. N., and Wikel, S. K. (1995). Dermacentor andersoni: salivary gland proteins suppressing T-lymphocyte responses to concanavalin A in vitro. Exp. Parasitol. 81, 262-271. doi: 10.1006/expr.1995.1117

Besse, A., Lamothe, B., Campos, A. D., Webster, W. K., Maddineni, U., Lin, S.-C., et al. (2007). TAK1dependent signaling requires functional interaction with TAB2/TAB3. J. Biol. Chem. 282, 3918-3928. doi: 10.1074/jbc.M608867200

Boulanger, N., Bulet, P., and Lowenberger, C. (2006). Antimicrobial peptides in the interactions between insects and flagellate parasites. Trends Parasitol. 22, 262-268. doi: 10.1016/j.pt.2006.04. 003

Boyden, E. D., and Dietrich, W. F. (2006). Nalp1b controls mouse macrophage susceptibility to anthrax 
lethal toxin. Nat. Genet. 38, 240-244. doi: 10.1038/ng1724

Brodsky, I. E., Palm, N. W., Sadanand, S., Ryndak, M. B., Fayyaz, S., Flavell, R. A., et al. (2010). A Yersinia secreted effecor protein promotes virulence by preventing inflammasome recognition of the type III secretion system. Cell Host Microbe 7, 376-387. doi: 10.1016/j.chom.2010.04.009

Calvo, E., Mans, B. J., Andersen, J. F., and Ribeiro, J. M. C. (2006). Function and evolution of a mosquito salivary protein family. J. Biol. Chem. 281, 19351942. doi: 10.1074/jbc.M510359200

Case, C. L. (2011). Regulating caspase1 during infection: roles of NLRs, AIM2, and ASC. Yale J. Biol. Med. 84, 333-343.

Centers for Disease Control and Prevention. (2010). Parasites - American Trypanosomiasis. Available at: http://www.cdc.gov/parasites/chagas/ disease.html (last modified November 2, 2010).

Centers for Disease Control and Prevention. (2011a). Yellow Fever. Available at: http://www.cdc.gov/yellowfever/ (last modified December 13, 2011).

Centers for Disease Control and Prevention. (2011b). Tularemia Statistics. Available at: http://www.cdc.gov/ tularemia/statistics/ (last modified September 29, 2011).

Centers for Disease Control and Prevention. (2012a). Dengue. Availble at: http://www.cdc.gov/dengue/epide miology/ (last modified September 27, 2012).

Centers for Disease Control and Prevention. (2012b). Lyme Disease Data. Available at: http://www.cdc. gov/lyme/stats/index.html (last modified September 10, 2012).

Centers for Disease Control and Prevention. (2012c). Plague. Available at: http://www.cdc.gov/plague/faq/ (last modified July 24, 2012).

Centers for Disease Control and Prevention. (2013a). Parasites Lymphatic Filariasis. Available at: http://www.cdc.gov/parasites/lymph aticfilariasis/gen_info/faqs.html (last modified June 14, 2013).

Centers for Disease Control and Prevention. (2013b). Parasites - Leishmaniasis. Available at: http://www.cdc.gov/parasites/leishma niasis/disease.html (last modified January 10, 2013).

Centers for Disease Control and Prevention. (2013c). Cases of West Nile Human Disease. Available at: www.cdc.gov/ncidod/dvbid/westnile/ qa/cases.htm (last modified August 13, 2013).

Centers for Disease Control and Prevention. (2013d). Annual Cases of Anaplasmosis in the United States. Available at: http://www.cdc. gov/anaplasmosis/stats/\#casesbyyear (last modified July 8, 2013).

Center for Infectious Disease Research and Policy. (2013). Tularemia: Current, Comprehensive Information on Pathogenesis, Microbiology, Epidemiology, Diagnosis, Treatment, and Prophylaxis. Available at: http://www.cidrap.umn.edu/cidrap/ content/bt/tularemia/biofacts/tulare miafactsheet.html\#_Public_Health_ Reporting_1 (last modified February 27, 2013).

Chamaillard, M., Hashimoto, M., Horie, Y., Masumoto, J., Qiu, S., Saab, L., et al. (2003). An essential role for NOD1 in host recognition of bacterial peptidoglycan containing diaminopimelic acid. Nat. Immunol. 4, 702-707. doi: 10.1038/ni945

Champagne, D. E. (2005). Antihemostatic molecules from saliva of blood-feeding arthropods. Pathophysiol. Haemost. Thromb. 34, 221227. doi: $10.1159 / 000092428$

Chen, G., Severo, M. S., Sohail, M., Sakhon, O. S., Wikel, S. K. and Kotsyfakis, M. (2012). Ixodes scapularis saliva mitigates inflammatory cytokine secretion during Anaplasma phagocytophilum stimulation of immune cells. Parasit. Vectors 5, 1. doi: 10.1186/1756-33055-229

Chmelar, J., Calvo, E., Pedra, J. H. F., Francischetti, I. M. B., and Kotsyfakis, M. (2012). Tick salivary secretion as a source of antihemostatics. J. Proteomics 75, 3842-3854. doi: 10.1016/j.jprot.2012.04.026

Chmelar, J., Oliveira, C. J., Rezacova, P. Francischetti, I. M. B., Kovarova, Z., Pejler, G., et al. (2011). A tick salivary protein targets cathepsin $\mathrm{G}$ and chymase and inhibits host inflammation and platelet aggregation. Blood 117, 736-744. doi: 10.1182/blood-201006-293241

Coban, C., Ishii, K. J., Horii, T. and Akira, S. (2007). Manipulation of host innate immune responses by the malaria parasite. Trends Microbiol. 15, 271-278. doi: 10.1016/j.tim.2007.04.003

Colonna, M. (2007). All roads lead to CARD9. Nat. Immunol. 8, 554-555. doi: 10.1038/ni0607-554

Cruz, A. R., Moore, M. W., La Vake, C. J., Eggers, C. H., Salazar, J. C., and Radolf, J. D. (2008). Phagocytosis of Borrelia burgdorferi, the Lyme disease spirochete, potentiates innate immune activation and induces apoptosis in human monocytes. Infect. Immun. 76, 56-70. doi: 10.1128/IAI.01039-07
Dai, J., Narasimhan, S., Zhang, L., Liu, L., Wang, P., and Fikrig, E. (2010). Tick histamine release factor is critical for Ixodes scapularis engorgement and transmission of the lyme disease agent. PLoS Pathog. 6:e1001205. doi: 10.1371/journal.ppat.1001205

Daix, V., Schroeder, H., Praet, N., Georgin, J.-P., Chiappino, I., Gillet, L., et al. (2007). Ixodes ticks belonging to the Ixodes ricinus complex encode a family of anticomplement proteins. Insect Mol. Biol. 16, 155-166. doi: 10.1111/j.1365-2583.2006.00710.x

Das, S., Banerjee, G., DePonte, K., Marcantonio, N., Kantor, F. S., and Fikrig, E. (2001). Salp25D, an Ixodes scapularis antioxidant, is 1 of 14 immunodominant antigens in engorged tick salivary glands. J. Infect. Dis. 184, 1056-1064. doi: 10.1086/323351

Davis, B. K., Wen, H., and Ting, J. P.-Y. (2011). The inflammasome NLRs in immunity, inflammation, and associated diseases. Annu. Rev. Immunol. 29, 707-735. doi: 10.1146/annurevimmunol-031210-101405

Demento, S. L., Eisenbarth, S. C., Foellmer, H. G., Platt, C., Caplan, M. J., Mark Saltzman, W., et al. (2009). Inflammasomeactivating nanoparticles as modular systems for optimizing vaccine efficacy. Vaccine 27, 3013-3021. doi: 10.1016/j.vaccine.2009.03.034

Déruaz, M., Frauenschuh, A., Alessandri, A. L., Dias, J. M., Coelho, F. M., Russo, R. C., et al. (2008). Ticks produce highly selective chemokine binding proteins with antiinflammatory activity. J. Exp. Med. 205, 2019 31. doi: 10.1084/jem.20072689

de Silva, A. M., Tyson, K. R., and Pal, U. (2009). Molecular characterization of the tick-Borrelia interface. Front. Biosci. 14:3051-3063. doi: $10.2741 / 3434$

Dostert, C., Guarda, G., Romero, J. F., Menu, P., Gross, O., Tardivel, A. et al. (2009). Malarial hemozoin is a Nalp3 inflammasome activating danger signal. PLoS ONE 4:e6510. doi: 10.1371/journal.pone.0006510

Edwards, J. F., Higgs, S., and Beaty, B. J. (1998). Mosquito feeding-induced enhancement of Cache Valley Virus (Bunyaviridae) infection in mice. J. Med. Entomol. 35, 261-265.

Faustin, B., Lartigue, L., Bruey, J.-M., Luciano, F., Sergienko, E., BaillyMaitre, B., et al. (2007). Reconstituted NALP1 inflammasome reveals two-step mechanism of caspase-1 activation. Mol. Cell 25, 713-724. doi: 10.1016/j.molcel.2007.01.032

Fernandes-Alnemri, T., Yu, J.-W., Juliana, C., Solorzano, L., Kang, S., Wu, J., et al. (2010). The AIM2 inflammasome is critical for innate immunity to Francisella tularensis. Nat. Immunol. 11, 385-393. doi: 10.1038/ni.1859

Ferwerda, B., McCall, M. B. B., de Vries, M. C., Hopman, J., Maiga, B., Dolo, A., et al. (2009). Caspase12 and the inflammatory response to Yersinia pestis. PLOS ONE 4:e6870. doi: 10.1371/journal.pone.0006870

Finney, C. A. M., Lu, Z., Lebourhis, L., Philpott, D. J., and Kain, K. C. (2009). Disruption of Nodlike receptors alters inflammatory response to infection but does not confer protection in experimental cerebral malaria. Infect. Immun. 80, 718-722.

Fontaine, A., Diouf, I., Bakkali, N., Missé, D., Pagès, F., Fusai, T., et al. (2011). Implication of haematophagous arthropod salivary proteins in host-vector interactions. Parasit. Vectors 4, 187. doi: 10.1186/1756-3305-4-187

Franchi, L., Muñoz-Planillo, R., and Núñez, G. (2012). Sensing and reacting to microbes through the inflammasomes. Nat. Immunol. 13, 325-332. doi: 10.1038/ni.2231

Francischetti, I. M. B., Sa-Nunes, A., Mans, B. J., Santos, I. M., and Ribeiro, J. M. C. (2009). The role of saliva in tick feeding. Front. Biosci. 14:20512088. doi: $10.2741 / 3363$

Frauenschuh, A., Power, C. A., Déruaz, M., Ferreira, B. R., Silva, J. S., Teixeira, M. M., et al. (2007). Molecular cloning and characterization of a highly selective chemokine-binding protein from the tick Rhipicephalus sanguineus. J. Biol. Chem. 282, 27250-27258. doi: 10.1074/jbc.M704706200

Frischknecht, F. (2007). The skin as interface in the transmission of arthropod-borne pathogens. Cell Microbiol. 9, 1630-1640. doi: 10.1111/j.1462-5822.2007.00955.x

Garg, R., Juncadella, I. J., Ramamoorthi, N., Ashish, Ananthanarayanan, S. K., Thomas, V., et al. (2006). CD4 is the receptor for the tick saliva immunosuppressor, Salp15. J. Immunol. 177, 6579-6583.

Gaucher, D., Therrien, R., Kettaf, N., Angermann, B. R., Boucher, G., FilaliMouhim, A., et al. (2008). Yellow fever vaccine induces integrated multilineage and polyfunctional immune responses. J. Exp. Med. 205, 311931131. doi: 10.1084/jem.20082292

Gazos-Lopes, F., Mesquita, R. D., SilvaCardoso, L., Senna, R., Silveira, A. B., Jablonka, W., et al. (2012). Glycoinositolphospholipids from Trypanosomatids subvert nitric oxide production in Rhodnius prolixus 
salivary glands. PLoS ONE 7:e47285. doi: 10.1371/journal.pone.0047285

Gillespie, R. D., Dolan, M. C., Piesman, J., and Titus, R. G. (2001). Identification of an IL-2 binding protein in the saliva of the Lyme disease vector tick, Ixodes scapularis. J. Immunol. 166, 4319-4326.

Gillespie, R. D., Mbow, M. L., and Titus, R. G. (2000). The immunomodulatory factors of bloodfeeding arthropod saliva. Parasite Immunol. 22, 319-331. doi: 10.1046/j.1365-3024.2000.00309.x

Girardin, S. E., Boneca, I. G., Viala, J., Chamaillard, M., Labigne, A., Thomas, G., etal. (2003a). Nod2 is a general sensor of peptidoglycan through muramyl dipeptide (MDP) detection. J. Biol. Chem. 278, 88698872. doi: 10.1074/jbc.C200651200

Girardin, S. E., Travassos, L. H., Hervé, M., Blanot, D., Boneca, I. G., Philpott, D. J., et al. (2003b). Peptidoglycan molecular requirements allowing detection by Nod1 and Nod2. J. Biol. Chem. 278, 41702-41708. doi: 10.1074/jbc.M307198200

Griffith, J. W., Sun, T., McIntosh, M. T., and Bucala, R. (2009). Pure hemozoin is inflammatory in vivo and activates the NALP3 inflammasome via release of uric acid. J. Immunol 183, 5208-5220. doi: 10.4049/jimmunol.0713552

Gringhuis, S. I., Kaptein, T. M., Wevers, B. A., Theelen, B., van der Vlist, M., Boekhout, T., et al. (2012). Dectin-1 is an extracellular pathogen sensor for the induction and processing of IL- $1 \beta$ via a noncanonical caspase- 8 inflammasome. Nat. Immunol. 13, 246-254. doi: 10.1038/ni.2222

Guo, X., Booth, C. J., Paley, M. A., Wang, X., DePonte, K., Fikrig, E. et al. (2009). Inhibition of neutrophil function by two tick salivary proteins. Infect. Immun. 77, 2320-2329. doi 10.1128/IAI.01507-08

Hall, L. R., and Titus, R. G. (1995). Vector saliva selectively modulates macrophage functions that inhibitk illing of. J. Immunol. 155, 3501-3506.

Hannier, S., Liversidge, J., Sternberg, J. M., and Bowman, A. S. (2004). Characterization of the B-cell inhibitory protein factor in Ixodes ricinus tick saliva: a potential role in enhanced Borrelia burgdoferi transmission. Immunology 113, 401-408. doi: 10.1111/j.1365-2567.2004.01975.x

Healthline. (2013). The Plague. Available at: http://www.health line.com/health/plague (accessed April 25, 2013).

Hitotsumatsu, O., Ahmad, R.C., Tavares, R., Wang, M. Philpott, D., Turer, E. E., et al.
(2008). The ubiquitin-editing enzyme A20 restricts nucleotidebinding oligomerization domain containing 2-triggered signals. Immunity 28, 381-390. doi: 10.1016/j.immuni.2008.02.002

Horka, H., Staudt, V., Klein, M. Taube, C., Reuter, S., Dehzad, N. et al. (2012). The tick salivary protein sialostatin L inhibits the Th9-derived production of the asthma-promoting cytokine IL- 9 and is effective in the prevention of experimental asthma. J. Immunol. 188, 2669-2676. doi 10.4049/jimmunol.1100529

Hotez, P. J., Fenwick, A., Savioli, L., and Molyneux, D. H. (2009). Rescuing the bottom billion through control of neglected tropical diseases. Lance 373, 1570-1575. doi: 10.1016/S01406736(09)60233-6

Hovius, J. W. R., de Jong, M. A. W. P., den Dunnen, J., Litjens, M., Fikrig, E., van der Poll, T., et al. (2008). Salp15 binding to DC-SIGN inhibits cytokine expression by impairing both nucleosome remodeling and mRNA stabilization. PLoS Pathog. 4:e31. doi: 10.1371/journal.ppat.0040031

Inohara, N., Koseki, T., del Peso, L., Hu, Y., Yee, C., Chen, S., et al. (1999). Nod1, an Apaf-1-like activator of caspase-9 and nuclear factor-кB. $J$. Biol. Chem. 274, 14560-14567. doi: 10.1074/jbc.274.21.14560

Kang, T.-B., Yang, S.-H., Toth, B., Kovalenko, A., and Wallach, D. (2013). Caspase- 8 blocks kinase RIPK3-mediated activation of the NLRP3 inflammasome. Immunity 38, 27-40. doi: 10.1016/j.immuni.2012.09.015

Katz, O., Waitumbi, J. N., Zer, R., and Warburg, A. (2000). Adenosine, AMP and protein phosphatase activity in sandfly saliva. Am. J. Trop. Med. Hyg. $62,145-50$.

Kaushik, D. K., Gupta, M., Kumawat, K. L., and Basu, A. (2012). NLRP3 inflammasome: key mediator of neuroinflammation in murine Japanese encephalitis. PLoS ONE 7:e32270. doi: 10.1371/journal.pone.0032270

Kayagaki, N., Warming, S., Lamkanfi, M., Vande Walle, L., Louie, S. Dong, J., etal. (2011). Noncanonical inflammasome activation targets caspase-11. Nature 479, 117 121. doi: 10.1038/nature 10558

Kobayashi, K., Inohara, N., Hernandez, L. D., Galán, J. E., Núñez, G., Janeway, C. A., et al. (2002). RICK/Rip2/CARDIAK mediates signalling for receptors of the innate and adaptive immune systems. Nature 416, 194-199. doi: 10.1038/416194a

Kotsyfakis, M., Horka, H., Salat, J., and Andersen, J. F. (2010). The crystal structures of two salivary cystatin from the tick Ixodes scapularis and the effect of these inhibitors on the establishment of Borrelia burgdorferi infection in a murine model. Mol. Microbiol. 77, 456-470. doi: 10.1111/j.1365-2958.2010.07220.x

Kotsyfakis, M., Karim, S., Andersen, J. F., Mather, T. N., and Ribeiro, J. M. C. (2007). Selective cysteine protease inhibition contributes to blood-feeding success of the tick Ixodes scapularis. J. Biol. Chem. 282, 29256-29263. doi: 10.1074/jbc M703143200

Kotsyfakis, M., Sá-Nunes, A., Francischetti, I. M. B., Mather, T. N. Andersen, J. F., and Ribeiro, J. M. C. (2006). Antiinflammatory and immunosuppressive activity of sialostatin L, a salivary cystatin from the tick Ixodes scapularis. J. Biol. Chem. 281, 26298-26307. doi: 10.1074/jbc M513010200

Kovats, R. S., Campbell-Lendrum, D. H., McMichel, A. J., Woodward, A., and Cox, J. S. H. (2001). Early effects of climate change: do they include changes in vector-borne disease? Philos. Trans. R. Soc. Lond B Biol. Sci. 356, 1057-1068. doi: 10.1098/rstb.2001.0894

Krause, P. J., Grant-Kels, J. M., Tahan, S. R., Dardick, K. R. Alarcon-Chaidez, F., Bouchard, K., et al. (2009). Dermatologic changes induced by repeated Ixodes scapularis bites and implications for prevention of tick-borne infection. Vector Borne Zoonotic Dis. 9, 603-610. doi 10.1089/vbz.2008.0091

Lamkanfi, M., and Dixit, V. M. (2011). Modulation of inflammasome pathways by bacterial and viral pathogens. J. Immunol. 187, 597-602. doi: 10.4049/jimmunol.1100229

LeBlanc, P. M., Yeretssian, G., Rutherford, N., Doiron, K., Nadiri, A. Zhu, L., et al. (2008). Caspase-12 modulates NOD signaling and regulates antimicrobial peptide production and mucosal immunity. Cell Host Microbe 3, 146-157. doi: 10.1016/j.chom.2008.02.004

Leboulle, G., Crippa, M., Decrem, Y., Mejri, N., Brossard, M., Bollen, A., et al. (2002). Characterization of a novel salivary immunosuppressive protein from Ixodes ricinus ticks. J. Biol. Chem. 277, 10083-10089. doi: 10.1074/jbc.M111391200

Levinsohn, J. L., Newman, Z. L., Hellmich, K. A., Fattah, R., Getz, M. A., Liu, S., et al. (2012). Anthrax lethal factor cleavage of Nlrp1 is required for activation of the inflammasome. PLoS Pathog. 8:e1002638. doi: 10.1371/journal.ppat.1002638
Lich, J. D., Ting, J. P., Carolina, N., and Hill, C. (2008). Monarch1/PYPAF7 and other CATERPILLER (CLR, NOD, NLR) proteins with negative regulatory functions. Microbes Infect. 9, 672-676. doi: 10.1016/j.micinf.2007.01.018

Lima-Junior, D. S., Costa, D. L., Carregaro, V., Cunha, L. D., Silva, A. L. N., Mineo, T. W. P., et al. (2013). Inflammasome-derived IL$1 \beta$ production induces nitric oxidemediated resistance to Leishmania. Nat. Med. 19, 909-15. doi: 10.1038/nm.3221

Lindgren, E., and Jaenson, T. G. (2006). "Lyme borreliosis in Europe: influences of climate and climate change, epidemiology, ecology and adaptation measures, " in Climate Change and Adaptation Strategies for Human Health, eds B. Menne and K. L. Ebi. Geneva: World Health Organization Europe.

Liu, N., Belperron, A. A., Booth, C. J., and Bockenstedt, L. K. (2009). The caspase 1 inflammasome is not required for control of murine Lyme borreliosis. Infect. Immun. 77, 33203327. doi: 10.1128/IAI.00100-09

Lögdberg, L., and Wester, L. (2000). Immunocalins: a lipocalin subfamily that modulates immune and inflammatory responses. Biochim. Biophys. Acta 1482, 284-297. doi: 10.1016/S0167-4838(00)00164-3

Mans, B. J., and Francischetti, I. M. B. (2011). Toxins and Hemostasis. Berlin: Springer, 21-44.

Martinon, F., Burns, K., and Tschopp, J. (2002). The inflammasome: a molecular platform triggering activation of inflammatory caspases and processing of pro-IL- $\beta$. Mol. Cell 10, 417-426. doi: 10.1016/S10972765(02)00599-3

McGraw, E. A., and O’Neill, S. L. (2013). Beyond insecticides: new thinking on an ancient problem. Nat. Rev. Microbiol. 11, 181-193. doi: 10.1038/nrmicro2968

MD Guidelines. (2013). Tularemia. Available at: http://www.mdguide lines.com/tularemia (accessed April $25,2013)$.

Medscape. (2013). Tularemia Epidemiology. Available at: http://emedi cine.medscape.com/article/230923overview\#a0199 (accessed April 25, 2013).

Mejia, J. S., Bishop, J. V., and Titus, R. G. (2006). Is it possible to develop pan-arthropod vaccines? Trends Parasitol. 22, 367-370. doi: 10.1016/j.pt.2006.06.001

Miao, E. A., Ernst, R. K., Dors, M., Mao, D. P., and Aderem, A. (2008). Pseudomonas aeruginosa activates caspase 
1 through Ipaf. Proc. Natl. Acad. Sci. U.S.A. 105, 2562-2567. doi: 10.1073/pnas.0712183105

Moreira, L. O., and Zamboni, D. S. (2012). NOD1 and NOD2 signaling in infection and inflammation. Front. Immunol. 3:328. doi: 10.3389/fimmu.2012.00328

Mulenga, A., Macaluso, K. R., Simser, J. A., and Azad, A. F. (2003). The American dog tick, Dermacentor variabilis, encodes a functional histamine release factor homolog. Insect Biochem. Mol. Biol. 33, 911-919. doi: 10.1016/S0965-1748(03)00097-3

Murray, P. J. (2005). NOD proteins: an intracellular pathogen-recognition system or signal transduction modifiers? Curr. Opin. Immunol. 17, 352-358. doi: 10.1016/ j.coi.2005.05.006

Nürnberger, T., Brunner, F., Kemmerling, B., and Piater, L. (2004). Innate immunity in plants and animals: striking similarities and obvious differences. Immunol. Rev. 198, 249-266. doi: 10.1111/j.01052896.2004.0119.x

Ockenhouse, C. F., Hu, W., Kester, K. E., Cummings, J. F., Stewart, A., Heppner, D. G., et al. (2006). Common and divergent immune response signaling pathways discovered in peripheral blood mononuclear cell gene expression patterns in presymptomatic and clinically apparent malaria. Infect. Immun. 74, 55615573. doi: 10.1128/IAI.00408-06

Oliveira, C. J. F., Sá-Nunes, A., Francischetti, I. M. B., Carregaro, V., Anatriello, E., Silva, J. S., et al. (2011). Deconstructing tick saliva: non-protein molecules with potent immunomodulatory properties. J. Biol. Chem. 286, 10960-10969. doi: 10.1074/jbc.M110.205047

Oosting, M., Berende, A., Sturm, P., Ter Hofstede, H. J. M., de Jong, D. J., Kanneganti, T.-D., et al. (2010). Recognition of Borrelia burgdorferi by NOD2 is central for the induction of an inflammatory reaction. J. Infect. Dis. 201, 1849-1858. doi: $10.1086 / 652871$

Oosting, M., van de Veerdonk, F. L., Kanneganti, T.-D., Sturm, P., Verschueren, I., Berende, A., et al. (2011). Borrelia species induce inflammasome activation and IL-17 production through a caspase-1-dependent mechanism. Eur. J. Immunol. 41, 172-181. doi: 10.1002/eji.201040385

Osorio, J. E., Godsey, M. S., Defoliart, G. R., and Yuill, T. M. (1996). La Crosse viremias in white-tailed deer and chipmunks exposed by injection or mosquito bite. Am. J. Trop. Med. Hyg. 54, 338-342.
Paesen, G. C., Adams, P. L., Harlos, K., Nuttall, P. A., and Stuart, D. I. (1999). Tick histamine-binding proteins: isolation, cloning, and threedimensional structure. Mol. Cell 3, 661-671. doi: 10.1016/S10972765(00)80359-7

Park, J.-H., Kim, Y.-G., McDonald, C., Kanneganti, T.-D., Hasegawa, M., Body-Malapel, M., et al. (2007). RICK/RIP2 mediates innate immune responses induced through Nod 1 and Nod2 but not TLRs. J. Immunol. 178, 2380-2386.

Parola, P., and Raoult, D. (2001). Ticks and tickborne bacterial diseases in humans: an emerging infectious threat. Clin. Infect. Dis. 32, 897-928. doi: 10.1086/319347

Pauleau, A.-L., and Murray, P. J. (2003). Role of Nod2 in the response of macrophages to Toll-like receptor agonists. Mol. Cell. Biol. 23, 75317539. doi: 10.1128/MCB.23.21.75317539.2003

Pedra, J. H. F., Sutterwala, F. S., Sukumaran, B., Ogura, Y., Qian, F., Montgomery, R. R., et al. (2007). ASC/PYCARD and caspase-1 regulate the IL-18/IFN- $\gamma$ axis during Anaplasma phagocytophilum infection. J. Immunol. 179, 4783-4791.

Petnicki-Ocwieja, T., DeFrancesco, A S., Chung, E., Darcy, C. T., Bronson, R. T., Kobayashi, K. S., et al. (2011). Nod2 suppresses Borrelia burgdorferi mediated murine lyme arthritis and carditis through the induction of tolerance. PLOS ONE 6:e17414. doi: 10.1371/journal.pone.0017414

Pierini, R., Juruj, C., Perret, M. Jones, C. L., Mangeot, P., Weiss, D. S., et al. (2012). AIM2/ASC triggers caspase-8-dependent apoptosis in Francisella-infected caspase1-deficient macrophages. Cell Death Differ. 19, 1709-1721. doi: 10.1038/cdd.2012.51

Preston, S. G., Majtán, J., Kouremenou, C., Rysnik, O., Burger, L. F., Cabezas Cruz, A., etal. (2013). Novel immunomodulators from hard ticks selectively reprogramme human dendritic cell responses. PLoS Pathog. 9:e1003450. doi: 10.1371/journal.ppat.1003450

Prevot, P.-P., Beschin, A., Lins, L., Beaufays, J., Grosjean, A., Bruys, L., etal. (2009). Exosites mediate the anti-inflammatory effects of a multifunctional serpin from the saliva of the tick Ixodes ricinus. FEBS J. 276, 3235-3246. doi: 10.1111/j.17424658.2009.07038.x

Ramamoorthi, N., Narasimhan, S., Pal, U., Bao, F., Yang, X. F., Fish, D., et al. (2005). The Lyme disease agent exploits a tick protein to infect the mammalian host. Nature 436, 573 577. doi: $10.1038 /$ nature 03812

Ramos, H. J., Lanteri, M. C., Blahnik, G., Negash, A., Suthar, M. S., Brassil, M. M., et al. (2012). IL$1 \beta$ signaling promotes $\mathrm{CNS}$-intrinsic immune control of West Nile virus infection. PLoS Pathog. 8:e1003039. doi: 10.1371/journal.ppat.1003039

Rathinam, V. A. K., Vanaja, S. K., Waggoner, L., Sokolovska, A., Becker, C., Stuart, L. M., et al. (2012). TRIF licenses caspase-11dependent NLRP3 inflammasome activation by gram-negative bacteria. Cell 150, 606-619. doi: 10.1016/j.cell.2012.07.007

Ray, K., Marteyn, B., Sansonetti, P. J., and Tang, C. M. (2009). Life on the inside: the intracellular lifestyle of cytosolic bacteria. Nat. Rev. Micro biol. 7, 333-340. doi: 10.1038/nrmicro2 112

Ribeiro, J. M. C., and Francischetti, I. M. B. (2003). Role of arthropod saliva in blood feeding: sialome and post-sialome perspectives. Annu. Rev. Entomol. 48, 73 88. doi: 10.1146/annurev.ento.48. 060402.102812

Rossol, M., Pierer, M., Raulien, N. Quandt, D., Meusch, U., Rothe, K., et al. (2012). Extracellular Ca2 + is a danger signal activating the NLRP3 inflammasome through $\mathrm{G}$ proteincoupled calcium sensing receptors. Nat. Commun. 3, 1329 . doi: 10.1038/ncomms2339

Rubin, R., and Strayer, D. S. (2012). Pathology: Chapter 2 Inflammation and Repair. Lippincott Williams \& Wilkins: USA.

Sabbah, A., Chang, T. H., Harnack, R., Frohlich, V., Tominaga, K., Dube, P. H., et al. (2009). Activation of innate immune antiviral responses by Nod2. Nat. Immunol. 10, 1073-1080. doi: 10.1038/ni.1782

Sabbatani, L. (1899). Fermento anticoagulante de l' "Ixodes ricinus." Arch. Ital. Biol. 31, 37-53.

Sangamnatdej, S., Paesen, G. C., Slovak, M., and Nuttall, P. A. (2002). A high affinity serotonin- and histaminebinding lipocalin from tick saliva. Insect Mol. Biol. 11, 79-86. doi: 10.1046/j.0962-1075.2001.00311.x

Sani, M. M., Hajizade, A., Sankian, M., Fata, A., Mellat, M., and Hassanpour, K. (2013). Evaluation of the expression of the inflammasome pathway related components in Leishmania major-infected murine macrophages. Eur. J. Exp. Biol. 3, 104-109.

Sá-Nunes, A., Bafica, A., Antonelli, L. R., Choi, E. Y., Francischetti, I. M. B., Andersen, J. F., et al. (2009). The immunomodulatory action of sialostatin L on dendritic cells reveals its potential to interfere with autoimmunity. J. Immunol. 182, 7422-7429. doi: 10.4049/jimmunol.0900075

Sá-Nunes, A., Bafica, A., Lucas, D. A., Conrads, P., Veenstra, T. D., Andersen, J. F., et al. (2007). Prostaglandin E2 is a major inhibitor of dendritic cell maturation and function in Ixodes scapularis saliva. J. Immunol. 179, 1497-1505.

Schroder, K., and Tschopp, J. (2010). The inflammasomes. Cell 140, 821832. doi: 10.1016/j.cell.2010.01.040

Schroeder, H., Daix, V., Gillet, L., Renauld, J.-C., and Vanderplasschen, A. (2007). The paralogous salivary anti-complement proteins IRAC I and IRAC II encoded by Ixodes ricinus ticks have broad and complementary inhibitory activities against the complement of different host species. Microbes Infect. 9, 247-250. doi: 10.1016/j.micinf.2006.10.020

Schuijt, T. J., Coumou, J., Narasimhan, S., Dai, J., Deponte, K., Wouters, D., et al. (2011). A tick mannosebinding lectin inhibitor interferes with the vertebrate complement cascade to enhance transmission of the lyme disease agent. Cell Host Microbe 10, 136-146. doi: 10.1016/j.chom.2011.06.010

Schuijt, T. J., Hovius, J. W. R., van Burgel, N. D., Ramamoorthi, N., Fikrig, E., and van Dam, A. P. (2008). The tick salivary protein Salp15 inhibits the killing of serumsensitive Borrelia burgdorferi sensu lato isolates. Infect. Immun. 76, 28882894. doi: 10.1128/IAI.00232-08

Shaw, M. H., Reimer, T., SánchezValdepeñas, C., Warner, N., Kim, Y.-G., Fresno, M., et al. (2009). T cell-intrinsic role of Nod 2 in promoting type 1 immunity to Toxoplasma gondii. Nat. Immunol. 10, 1267-1274. doi: 10.1038/ni.1816

Shimada, K., Crother, T. R., Karlin, J., Dagvadorj, J., Chiba, N., Chen, S., et al. (2012). Oxidized mitochondrial DNA activates the NLRP3 inflammasome during apoptosis. Immunity 36, 401-414. doi: 10.1016/j.immuni.2012.01.009

Shio, M. T., Tiemi Shio, M., Eisenbarth, S. C., Savaria, M., Vinet, A. F., Bellemare, M.-J., et al. (2009). Malarial hemozoin activates the NLRP3 inflammasome through Lyn and Syk kinases. PLoS Pathog. 5:e1000559. doi: 10.1371/journal.ppat.1000559

Silva, G. K., Gutierrez, F. R. S., Guedes, P. M. M., Horta, C. V., Cunha, L. D., Mineo, T. W. P., etal. (2010). Cutting edge: nucleotide-binding oligomerization domain 1-dependent responses 
account for murine resistance against Trypanosoma cruzi infection. J. Immunol. 184, 1148-1152. doi: 10.4049/jimmunol.0902254

Soares, C. A. G., Lima, C. M. R. Dolan, M. C., Piesman, J., Beard, C. B., and Zeidner, N. S. (2005). Capillary feeding of specific dsRNA induces silencing of the Isac gene in nymphal Ixodes scapularis ticks. Insect Mol. Biol. 14, 443-452. doi: 10.1111/j.1365-2583.2005.00575.x

Sterka, D., Rati, D. M., and Marriott, I. (2006). Functional expression of NOD2, a novel pattern recognition receptor for bacterial motifs, in primary murine astrocytes. Glia 53 , 322-330. doi: 10.1002/glia.20286

Strowig, T., Henao-Mejia, J., Elinav, E., and Flavell, R. (2012). Inflammasomes in health and disease. Nature 481, 278-286. doi: 10.1038/ nature 10759

Styer, L. M., Lim, P.-Y., Louie, K. L., Albright, R. G., Kramer, L. D., and Bernard, K. A. (2011). Mosquito saliva causes enhancement of West Nile virus infection in mice. J. Virol. 85, 1517-1527. doi: 10.1128/JVI.01112-10

Sukumaran, B., Ogura, Y., Pedra, J. H. F., Kobayashi, K. S., Flavell, R. A., and Fikrig, E. (2012). Receptor interacting protein-2 contributes to host defense against Anaplasma phagocytophilum infection. FEMS Immunol. Med. Microbiol. 66, 211-219. doi: 10.1111/j.1574-695X.2012.01001.x

The New York Times. (2013). Lyme Disease. Available at: http://health. nytimes.com/health/guides/disease/ lyme-disease/risk-factors.html (accessed April 25, 2013).

Titus, R. G., Bishop, J. V., and Mejia, J. S. (2006). The immunomodulatory factors of arthropod saliva and the potential for these factors to serve as vaccine targets to prevent pathogen transmission. Parasite Immunol. 28, 131-141.

Titus, R. G., and Ribeiro, J. M. (1988). Salivary gland lysates from the sand fly Lutzomyia longipalpis enhance Leishmania infectivity. Science 239, 1306-1308. doi: 10.1126/science.3344436

Titus, R. G., and Ribeiro, J. M. (1990). The role of vector saliva in transmission of arthropod-borne disease. Parasitol. Today 6, 157-160. doi: 10.1016/0169-4758(90)90338-5
Travassos, L. H., Carneiro, L. A. M., Ramjeet, M., Hussey, S., Kim, Y.G., Magalhães, J. G., etal. (2010). Nod1 and Nod2 direct autophagy by recruiting ATG16L1 to the plasma membrane at the site of bacterial entry. Nat. Immunol. 11, 55-62. doi: 10.1038/ni.1823

Tyson, K., Elkins, C., Patterson, H., Fikrig, E., and de Silva, A. (2007). Biochemical and functional characterization of Salp20, an Ixodes scapularis tick salivary protein that inhibits the complement pathway. Insect Mol. Biol. 16, 469-479. doi: 10.1111/j.1365-2583.2007.00742.x

Tyson, K. R., Elkins, C., and de Silva, A. M. (2008). A novel mechanism of complement inhibition unmasked by a tick salivary protein that binds to properdin. J. Immunol. 180, $3964-$ 3968.

Ullmann, A. J., Dolan, M. C., Sackal, C. A., Fikrig, E., Piesman, J., and Zeidner, N. S. (2013). Immunization with adenoviral-vectored tick salivary gland proteins (SALPs) in a murine model of Lyme borreliosis. Ticks Tick Borne Dis. 4, 160-163. doi: 10.1016/j.ttbdis.2012.08.006

Valenzuela, J. G., Charlab, R., Mather, T. N., and Ribeiro, J. M. (2000). Purification, cloning, and expression of a novel salivary anticomplement protein from the tick, Ixodes scapularis. J. Biol. Chem. 275, 18717-18723. doi: 10.1074/jbc.M001486200

Vaughan, J. A., Scheller, L. F., Wirtz, R. A., and Azad, A. F. (1999). Infectivity of Plasmodium berghei sporozoites delivered by intravenous inoculation versus mosquito bite: implications for sporozoite vaccine trials. Infect. Immun. 67, 4285-4289.

Vladimer, G. I., Weng, D., Paquette, S. W. M., Vanaja, S. K., Rathinam, V. A. K., Aune, M. H., et al. (2012). The NLRP12 inflammasome recognizes Yersinia pestis. Immunity 37, 96-107. doi: 10.1016/j.immuni.2012.07.006

Wang, H., and Nuttall, P. A. (1999). Immunoglobulin-binding proteins in ticks: new target for vaccine development against a blood-feeding parasite. Cell Mol. Life. Sci. 56, 286-295. doi: $10.1007 / \mathrm{s} 000180050430$

Wang, H., and Nuttall, P. A. (1995). Immunoglobulin-G binding proteins in the ixodid ticks, Rhipicephalus appendiculatus, Amblyomma variegatum and Ixodes hexagonus. Parasitology 111, 161-165. doi: 10.1017/S0031182000064908

Wang, H., Paesen, G. C., Nuttall, P. A., and Barbour, A. G. (1998) Male ticks help their mates to feed. Nature 391, 753-4. doi: 10.1038/ 35773

Wang, L., Manji, G. A., Grenier, J. M., Al-Garawi, A., Merriam, S., Lora, J. M., et al. (2002). PYPAF7, a novel PYRIN-containing Apaf1-like protein that regulates activation of NF-кB and caspase-1dependent cytokine processing. J. Biol. Chem. 277, 29874-29880. doi: 10.1074/jbc.M203915200

Wilmanski, J. M., Petnicki-Ocwieja, T., and Kobayashi, K. S. (2008). NLR proteins: integral members of innate immunity and mediators of inflammatory diseases. J. Leukoc. Biol. 83, 13-30. doi: 10.1189/jlb.0607402

World Health Organization. (2013a). World Malaria Report 2011. Available at: http://www.who.int/mala ria/publications/atoz/978924156440 3/en/index.html (accessed April 24, 2013).

World Health Organization. (2013b). Impact of Dengue. Available at: http://www.who.int/csr/disease/den gue/impact/en/index.html (accessed April 24, 2013).

World Health Organization. (2013c). West Nile Virus. Available at: http://www.who.int/mediacentre/fac tsheets/fs354/en/ (accessed April 25, 2013)

World Health Organization. (2013d). Chagas Disease. Available at: http://www.who.int/mediacentre/fac tsheets/fs340/en/ (accessed April 25, 2013).

World Health Organization. (2013e). Yellow Fever. Available at: http://www.who.int/mediacentre/fac tsheets/fs100/en/ (accessed April 25, 2013).

Wu, M.-F., Chen, S.-T., Yang, A.-H., Lin, W.-W., Lin, Y.-L., Chen, N.-J., et al. (2013). CLEC5A is critical for dengue virus-induced inflammasome activation in human macrophages. Blood 121, 95-106. doi: 10.1182/blood2012-05-430090

Zaki, M. H., Vogel, P., Malireddi, R. K. S., Body-Malapel, M., Anand, P. K., Bertin, J., et al. (2011) The NOD-like receptor NLRP12 attenuates colon inflammation and tumorigenesis. Cancer Cell 20, 649660. doi: 10.1016/j.ccr.2011.10.022

Zeidner, N. S., Higgs, S., Happ, C. M., Beaty, B. J., and Miller, B. R. (1999). Mosquito feeding modulates Th1 and Th2 cytokines in flavivirus susceptible mice: an effect mimicked by injection of sialokinins, but not demonstrated in flavivirus resistant mice. Parasite Immunol. 21, 35-44. doi: 10.1046/j.13653024.1999.00199.x

Zhao, Y., Yang, J., Shi, J., Gong, Y.-N., Lu, Q., Xu, H., et al. (2011). The NLRC4 inflammasome receptors for bacterial flagellin and type III secretion apparatus. Nature 477, 596-600. doi: 10.1038/ nature 10510

Zheng, Y., Lilo, S., Brodsky, I. E., Zhang, Y., Medzhitov, R., Marcu, K. B., etal. (2011). A Yersinia effector with enhanced inhibitory activity on the NF- $\kappa$ B pathway activates the NLRP3/ASC/caspase1 inflammasome in macrophages. PLoS Pathog. 7:e1002026. doi: 10.1371/journal.ppat.1002026

Conflict of Interest Statement: The authors declare that the research was conducted in the absence of any commercial or financial relationships that could be construed as a potential conflict of interest.

Received: 23 August 2013; paper pending published: 13 September 2013; accepted: 26 September 2013; published online: 21 October 2013.

Citation: Sakhon OS, Severo MS, Kotsyfakis M and Pedra JHF (2013) A Nod to disease vectors: mitigation of pathogen sensing by arthropod saliva. Front. Microbiol. 4:308. doi: 10.3389/fmicb. 2013.00308

This article was submitted to Microbial Immunology, a section of the journal Frontiers in Microbiology.

Copyright (c) 2013 Sakhon, Severo, Kotsyfakis and Pedra. This is an open-access article distributed under the terms of the Creative Commons Attribution License (CC BY). The use, distribution or reproduction in other forums is permitted, provided the original author(s) or licensor are credited and that the original publication in this journal is cited, in accordance with accepted academic practice. No use, distribution or reproduction is permitted which does not comply with these terms. 